\title{
A Retrospective Study of the Related Common factors of COVID-19
}

\author{
Xuejun Lu ${ }^{1}$, Haifeng Zhang ${ }^{2 *}$, Isaac Kumi Adu ${ }^{2,3}$, Zhi Xiong ${ }^{2}$, Yongxiang Zheng ${ }^{1}$, Jiachong Wang ${ }^{1}$
}

\author{
${ }^{1}$ Department of Emergency Intensive Care Unit, the Central South University Xiangya School of Medicine Affiliated Haikou Hospital, Haikou 570208, CHINA \\ ${ }^{2}$ Department of Respiratory Medicine, The Second Hospital of Jingzhou \& the Affiliated Hospital of Hubei College of Chinese Medicine, Jingzhou 434000, CHINA \\ ${ }^{3}$ Health Science Center, Yangtze University, Jingzhou 434000, CHINA \\ *Corresponding Author: 507109398@qq.com
}

Citation: Lu XJ, Zhang HF, Adu IK, Xiong Z, Zheng YX, Wang JC. A Retrospective Study of the Related Common factors of COVID-19. Electron J Gen Med. 2021;18(1):em262. https://doi.org/10.29333/ejgm/8548

\section{ARTICLE INFO}

Received: 23 Apr. 2020

Accepted: 22 Jul. 2020

\section{ABSTRACT}

Objective: To provide reference for prevention and control of SARS-CoV-2 infection through analysis of related factors of patients diagnosed and suspected with COVID-19.

Methods: Data of 40 confirmed cases and 24 suspected cases of COVID-19 admitted from January to February 2020 in the Second People's Hospital of Jingzhou City were collected, and the differences in indicators and related factors between the confirmed and suspected groups were compared.

Results: There was no significant difference in patients age and APACHE II score between the two groups $(P>0.05)$. Compared with the suspected group, WBC and Neut decreased in the diagnosed group, and the difference was statistically significant $(p<0.05)$. PCT, Lymph, hs-CRP, ALT, IL-6, LDH, CK and other indicators including; gender, fever, dry cough, limb soreness, fatigue, underlying disease, were not statistically significant $(p>0.05)$. There was no significant difference in the factors such as single lung lobe lesions and multiple lobe lesions $(P>0.05)$.

Conclusion: There is no significant difference between the common COVID-19 patients and the suspected patients in terms of population characteristics, clinical manifestations and most laboratory tests.

Keywords: 2019 coronavirus disease, SARS-COV-2, COVID-19

\section{INTRODUCTION}

In late December, 2019, a novel Coronavirus infection emerged in Wuhan as an outbreak [1,2]. The infection was then named Coronavirus disease 2019 (COVID-19) by the WHO [3]. The virus was reported to belong to beta-Coronavirus with phylogenetic similarity of SARS-CoV [4], and was subsequently named severe acute respiratory syndrome Coronavirus 2, SARS-CoV-2 [5]. Since the population is generally susceptible, prevention of the transmission route is not easy to be effectuated. Therefore, COVID-19 has apparently become a global pandemic from an epidemic in just few months [6]. Globally, 234, 079 confirmed cases have been reported as at March 19, 2020 with 9840 deaths worldwide [7]. Additionally, infected individuals can be asymptomatic carriers [8], and patients with mild cases of COVID-19 may exhibit varying clinical manifestations making it difficult to making it difficult to make a differential diagnosis and increasing the difficulty of prevention and control. Early studies mentioned fever, dry cough, chest pain, difficulty in breathing and fatigue as the clinical characteristics of individuals infected with SARS-CoV-2 $[1,2,4,9]$. In this study, we retrospectively analyze a total of 64 suspected and confirmed cases of COVID-19 treated during late January and February, 2020 in Jingzhou City in Hubei Province and explored the relevant factors of COVID-19 to provide a reference for clinical identification.

\section{MATERIALS AND METHODS}

\section{Collection of General Information}

Forty cases of COVID-19 confirmed, and twenty-four suspected cases were admitted to the Second People's Hospital of Jingzhou City from January to February 2020. Of the confirmed cases, the mild type was the main types hospitalized (39 cases of mild type, 1 of moderate type). The selected cases in this study are in line with the National Health and Health Commission's "Pneumonitis Diagnosis and Treatment Scheme for New Coronavirus Infection (First Edition)" [10] and "New Coronavirus Infection Pneumonia Diagnosis and Treatment (Sixth Edition)" [11]. Diagnostic criteria; confirmed cases were throat swab samples RT-PCR test SARS-CoV-2 nucleic acid positive.

\section{Methods}

Collecting patient data include: age, gender, APACHE II score, clinical symptoms (fever, dry cough, fatigue, sore limbs), underlying diseases (cardiovascular disease, COPD, diabetes, malignant tumors), imaging changes (single lung lobe lesions, Multilobe lesions), White Blood Cell (WBC), Neutrophil (Neut), Lymphocyte (Lymph), High Sensitivity C Reactive Protein (hsCRP), Procalcitonin (PCT), Alanine aminotransferase (ALT), Interleukin-6 (IL-6), Lactate Dehydrogenase (LDH), Creatine kinase (Creatine Kinase, $\mathrm{CK}$ ) and so on. The patients were divided into a confirmed group and a suspected group. 
Table 1. Comparison of general information and laboratory testing indicators

\begin{tabular}{ccc}
\hline & Diagnosed group & Suspected group \\
\hline AGE (YEARS) & $44.4 \pm 13.19$ & $42.21 \pm 13.56$ \\
\hline APACHE II (SCORE) & $2.53 \pm 1.80$ & $2.25 \pm 1.76$ \\
\hline PCT (pg/ml) & $0.07 \pm 0.07$ & $0.19 \pm 0.57$ \\
\hline WBC $\left(10^{\wedge} 9 / \mathrm{L}\right)$ & $4.62 \pm 1.91^{\mathrm{a}}$ & $6.17 \pm 2.20$ \\
\hline Neut $\left(10^{\wedge} 9 / \mathrm{L}\right)$ & $3.12 \pm 1.74^{\mathrm{a}}$ & $4.14 \pm 2.17$ \\
\hline Lymph $\left(10^{\wedge} 9 / \mathrm{L}\right)$ & $1.21 \pm 0.42$ & $1.38 \pm 0.45$ \\
\hline Hs-CRP $(\mathrm{mg} / \mathrm{L})$ & $17.73 \pm 28.79$ & $31.18 \pm 27.95$ \\
\hline ALT $(\mathrm{U} / \mathrm{L})$ & $31.15 \pm 41.61$ & $37.75 \pm 29.07$ \\
\hline LDH (U/L) & $193.35 \pm 62.16$ & $177.5 \pm 64.72$ \\
\hline IL-6 (pg/ml) & $9.15 \pm 16.62$ & $7.71 \pm 8.61$ \\
\hline CK (U/L) & $219.25 \pm 659.57$ & $139.75 \pm 127.90$ \\
\hline Note: Compared with the suspected group, ${ }^{\mathrm{a}} p<0.05$
\end{tabular}

Table 2. COVID-19 infection single factor analysis

\begin{tabular}{ccccc}
\hline Factor & $\begin{array}{c}\text { Diagnosed } \\
\text { group }\end{array}$ & $\begin{array}{c}\text { Suspected } \\
\text { group }\end{array}$ & $\begin{array}{c}\boldsymbol{\chi} \mathbf{2} \\
\text { value }\end{array}$ & $\boldsymbol{P}$ value \\
\hline $\begin{array}{c}\text { Gender } \\
\text { (Male /Female) }\end{array}$ & $20 / 20$ & $13 / 11$ & 0.104 & $P>0.05$ \\
\hline $\begin{array}{c}\text { Fever } \\
\text { (Present / Absent) }\end{array}$ & $33 / 7$ & $20 / 4$ & 0.007 & $P>0.05$ \\
\hline $\begin{array}{c}\text { Dry cough } \\
\text { (Present / Absent) }\end{array}$ & $31 / 9$ & $15 / 9$ & 1.670 & $P>0.05$ \\
\hline $\begin{array}{c}\text { Fatigue } \\
\text { (Present / Absent) }\end{array}$ & $24 / 16$ & $11 / 13$ & 1.215 & $P>0.05$ \\
\hline $\begin{array}{c}\text { Limbs soreness } \\
\text { (Present /Absent) }\end{array}$ & $8 / 32$ & $2 / 22$ & 0.790 & $P>0.05$ \\
\hline $\begin{array}{c}\text { Underlying disease } \\
\text { (Present / Absent) }\end{array}$ & $12 / 28$ & $3 / 21$ & 2.560 & $P>0.05$ \\
\hline $\begin{array}{c}\text { Single lung lobe lesion } \\
\text { (Present / Absent) }\end{array}$ & $7 / 33$ & $6 / 18$ & 0.521 & $P>0.05$ \\
\hline $\begin{array}{c}\text { Multilobe lesion } \\
\text { (Present / Absent) }\end{array}$ & $32 / 8$ & $16 / 8$ & 1.422 & $P>0.05$ \\
\hline
\end{tabular}

All the above data were collected and entered into the EXCEL form for basic data analysis. SPSS software was used to perform single factor analysis on the data of suspected and confirmed cases.

\section{Statistical Methods}

SPSS 17.0 was used for data analysis. Measurement data are expressed as mean \pm standard deviation ( \pm s), using independent sample $t$ test; count data are expressed as cases and percentages, using $x 2$ test. $p<0.05$ was considered statistically significant.

\section{RESULTS}

\section{General Information}

Among the 40 patients diagnosed, the age was 23 to 68 years, the average age was $44.4 \pm 13.19$ years, and the average APACHE II score was $2.53 \pm 1.80$ points. Among the 24 suspected patients, the age was 23 to 65 years, and the average age 42.21 \pm 13.56 years old, the average APACHE II score was $2.25 \pm$ 1.76 points. There was no significant difference in age and APACHE II score between the two groups ( $P>0.05)$, and the data were balanced and comparable. See Table 1.

\section{Comparison of Related Indicators between the Two Groups}

Compared with the suspected group, the WBC and Neut in the diagnosed group decreased, and the differences were statistically significant $(p<0.05)$; the remaining PCT, Lymph, hsCRP, ALT, IL-6, LDH and CK, the differences were not statistically significant ( $p>0.05)$. See Table 1.

\section{Univariate Analysis of COVID-19 Infection}

Gender, fever, dry cough, limbs soreness, fatigue, underlying disease, single lobe disease, multilobe disease and other factors were not uniformly different between the two groups. See Table 2.

\section{DISCUSSION}

From the statistical data of this study, the average age of the diagnosed group was $44.4 \pm 13.19$ years, the ratio of males and females was low, and the APACHE II score was low, which confirmed the general population's susceptibility of the SARSCoV-2 infection. The mildly infected patients are mainly young and middle-aged individuals. There was no statistical difference in age, gender, APACHE II score, and underlying diseases between the suspected and confirmed groups, suggesting that there were no differences in the characteristics of the two groups, which increased the difficulty of early identification and prevention. In bacterial infections, patients with inflammation indicators such as WBC, Neut, and PCT often increase significantly. Among them, PCT is a sensitive and specific biomarker reflecting the bacterial infection of the body [9]. In this study, there were clinical changes and imaging changes in patients, and no significant changes were found in indicators such as WBC, Neut, and PCT, which were consistent with the characteristics of viral infection. However, WBC and Neut in the confirmed group were lower than those in the suspect group, which may be a potential distinguishing indicator. In a study by Zhang JJ et al. [12], it was also found that a reduction in Neut was often present in COVID-19 patients. In this study, Hs-CRP and IL- 6 were slightly high in both groups, but the difference was not statistically significant. CRP as an acute phase response protein can be significantly increased during infection and tissue damage, significantly increased during bacterial infection, and normal or slightly elevated during viral infection. IL-6 is an important cytokine expressed by the immune system in response to injury and early infection. Its elevated level is positively correlated with the severity of the infection. CRP and IL- 6 can also be elevated in a non-infective state, resulting in a lack of specificity for infection [13]. LDH and CK are higher in skeletal muscle and myocardium of the body, and will increase significantly when myolysis and myocardial injury occur. Muscle soreness was found in $20 \%$ of the patients diagnosed in this study, and only $8.3 \%$ of the suspected patients. The LDH in both groups was within the normal range. Although the $\mathrm{CK}$ in the diagnosed group increased, there was no statistical difference compared with the suspected group.

In this study, $82.8 \%$ of patients had fever, $71.9 \%$ had dry cough, and $54.7 \%$ were fatigued (Figure 1). Also, $15.6 \%$ had limb soreness and $24 \%$ had underlying diseases. Imaging study of the patients showed $20.3 \%$ with a single lobe lesion while $75 \%$ had multi-lobe lesions (Figure 2 ).

A univariate analysis was performed, and the results showed that there were no differences between the two groups of factors such as fever, dry cough, sore limbs, fatigue, underlying diseases, single lung lobe lesion, and multiple lung lobes lesion indicating that the mild COVID- 19 patients and 


\section{Gender}
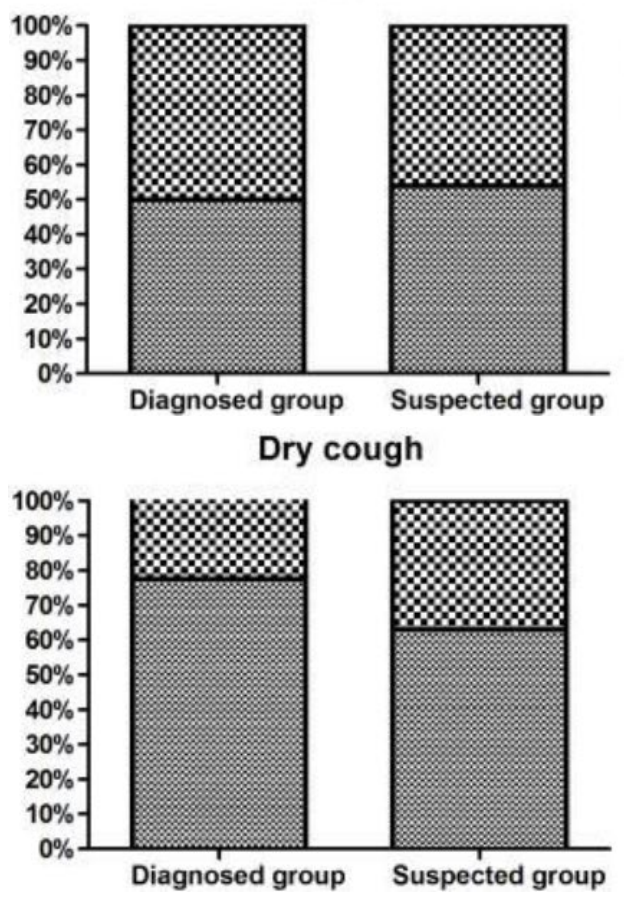

Figure 1. Percentages of the gender and most common factors
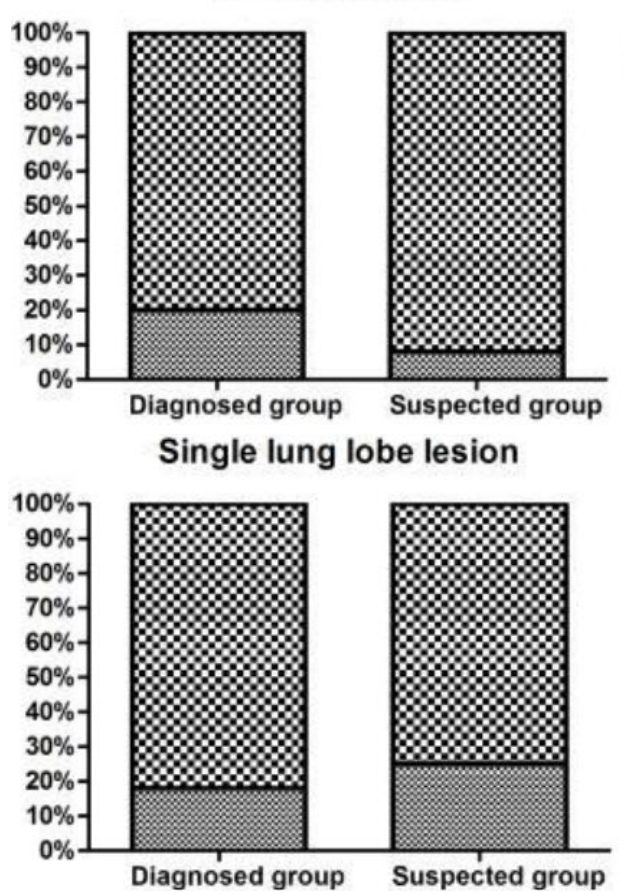

Figure 2. Percentages of other factors and imaging features

suspected patients' characteristics are more difficult distinguishing therefore, nucleic acid detection is an important means for their diagnosis. However, the sensitivity and specificity of the SARS-CoV-2 test have not been fully studied [14]. The positive rates of different respiratory samples are distinct, and the positive rates of patients with different disease levels are also distinct [15]. The SARS-CoV-2 nucleic acid test specimens in this study were all throat swabs. The sampling personnel's level and operating methods can also influence the positive rate.
Fever

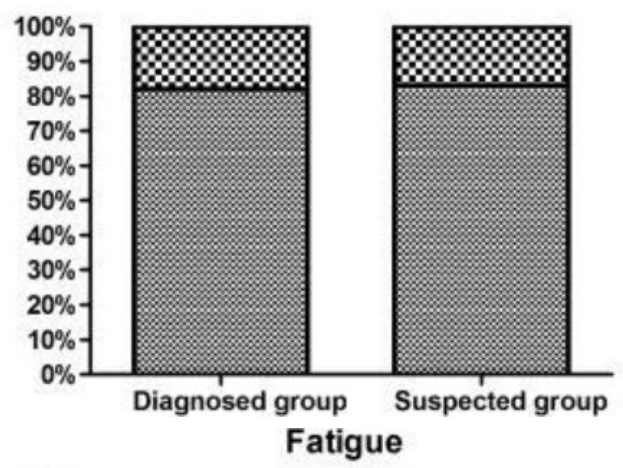

Present

$\infty$ Absent

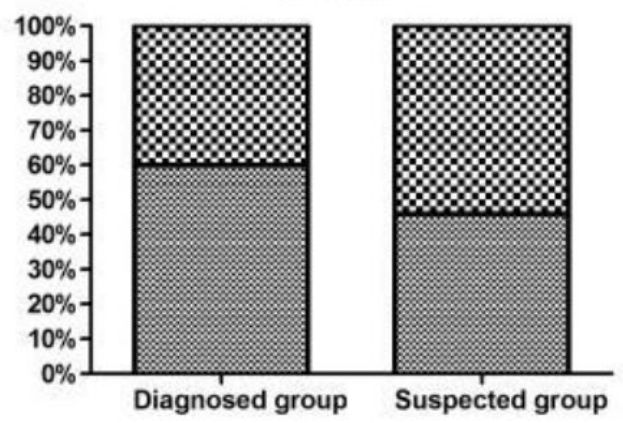

Present

Absent
Underlying disease

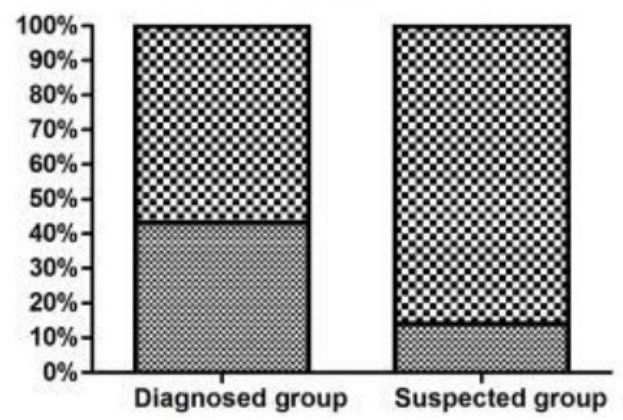

Multilobe lesion

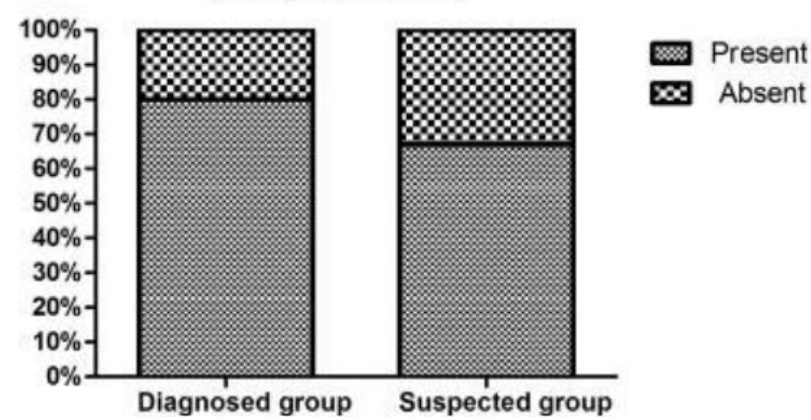

Through this study, we found that patients with mild COVID-19 were not significantly different from suspected patients in terms of population characteristics, clinical manifestations, laboratory testing, and imaging. The diagnosis can only be confirmed by nucleic acid testing or gene sequencing, which enhances early epidemic prevention and control.

\section{Limitation}

This study has some limitations. First, the interpretation of our findings was limited to our study sample which was small. 
Future large sample studies are encouraged. Secondly, lack of normal population control, making it difficult to know the difference from normal population. And lastly, our data mainly consisted of the mild type COVID-19 cases, and this study can be enriched if different types of patients including severe and critical cases are included.

\section{CONCLUSION}

There is a potential diagnostic dilemma for establishing a differential diagnosis given that there is no significant difference between patients with suspected and confirmed COVID-19 cases. Only Nucleic acid testing or gene sequencing can confirm the diagnosis. This makes early epidemic prevention and control difficult to execute. Therefore, suspected cases should be isolated and tested timely. Treatment should be instituted early with optimization for confirmed cases.

\section{ABBREVIATION}

COVID-19 : 2019 Coronavirus disease

SARS-CoV-2 : Severe Acute Respiratory Syndrome-related Coronavirus 2

APACHE II : Acute Physiology and Chronic Health Evaluation II

$\begin{array}{ll}\text { WBC } & \text { : White Blood Cell } \\ \text { Neut } & \text { : Neutrophil } \\ \text { Lymph } & : \text { Lymphocyte } \\ \text { hs-CRP } & \text { : High Sensitivity C Reactive Protein } \\ \text { PCT } & \text { : Procalcitonin } \\ \text { ALT } & \text { : Alanine aminotransferase } \\ \text { IL-6 } & \text { : Interleukin-6 } \\ \text { LDH } & : \text { Lactate Dehydrogenase Creatine kinase } \\ \text { CK } & : \text { Creatine Kinase } \\ \text { WHO } & : \text { World Health Organization }\end{array}$

Author contributions: All authors have sufficiently contributed to the study, and agreed with the results and conclusions.

Funding: No funding source is reported for this study.

Declaration of interest: No conflict of interest is declared by authors.

\section{REFERENCES}

1. Wang C, Horby PW, Hayden FG, Gao GF. A novel coronavirus outbreak of global health concern. Lancet 2020;395:470-3. https://doi.org/10.1016/S0140-6736(20)30185-9

2. Munster VJ, Koopmans M, van Doremalen N, van Riel D, de Wit E. A novel coronavirus emerging in China-key questions for impact assessment. N. Engl. J. Med., 2020;382:692-4. https://doi.org/10.1056/NEJMp2000929 PMid:31978293
3. Coronavirus disease (COVID-19) outbreak (World Health Organization, 2020); Available at: https://www.who.int/ emergencies/diseases/novel-coronavirus-2019

4. Zhu N, Zhang D, Wang W, et al A novel coronavirus from patients with pneumonia in China, 2019. N Engl J Med 2020;382:727-33. https://doi.org/10.1056/NEJMoa2001017 PMid:31978945 PMCid:PMC7092803

5. Gorbalenya AE, Baker SC, Baric RS, et al. The species Severe acute respiratory syndrome-related coronavirus: classifying 2019-nCoV and naming it SARS-CoV-2. Nat Microbiol 2020. https://doi.org/10.1038/s41564-020-0695-z PMid:32123347 PMCid:PMC7095448

6. WHO Director-General's opening remarks at the media briefing on COVID-19 - 11 March 2020. Available at: https://www.who.int/dg/speeches/detail/who-directorgeneral-s-opening-remarks-at-the-media-briefing-oncovid-19---11-march-2020

7. World Health Organization Coronavirus disease (COVID2019) situation report-60, 2020. Available at: https://www.who.int/emergencies/diseases/novelcoronavirus-2019/situation-reports

8. Hu Z, Song C, Xu C, et al. Clinical Characteristics of 24 Asymptomatic Infections with COVID-19 Screened among Close Contacts in Nanjing, China medRxiv preprint. https://doi.org/10.1101/2020.02.20.202025619

9. Liu $\mathrm{H}$, Liu $\mathrm{G}, \mathrm{Ma} \mathrm{Q}$. The value of procalcitonin in early diagnosis of emergency sepsis patients. Chinese Critical Care Medicine, 2012;24(5):298-301. https://doi.org/10.3760 /cma.j.issn.1003-0603.2012.05.011

10. Diagnosis and treatment of pneumonia caused by a new coronavirus (first edition) Available at: http://www.mammal.cn//EN/Y2007/V27/I1/86

11. Diagnosis and treatment of pneumonia caused by a new coronavirus infection (Sixth edition). Chinese Journal of Infection Control 2020;19(02):192-5. https://doi.org/ 10.12138/j.issn.1671-9638.20206154

12. Zhang JJ, Dong X, Cao YY, et al. Clinical characteristics of 140 patients infected with SARS-CoV-2 in Wuhan, China [published online ahead of print, 2020 Feb 19]. Allergy. 2020;10. https://doi.org/10.1111/all.14238 PMid:32077115

13. Kruger S, Ewig S, Papassotiriou J, et al. Inflammatory parameters predict etiologic in patterns but do not allow for individual prediction of etiology in patients with CAP: results from the German competence network CAPNETZ. Respir Res, 2009;10:65. https://doi.org/10.1186/s13613016-0114-z PMid:27316915 PMCid:PMC4912513

14. Yang $Y$, Yang $M$, Shen $C$, et al. Evaluating the accuracy of different respiratory specimens in the laboratory diagnosis and monitoring the viral shedding of 2019-nCoV infections. medRxiv preprint. https://doi.org/10.1101/2020.02.11. 20021493

15. Xiao SY, Wu Y, Liu H. Evolving status of the 2019 novel coronavirus Infection: proposal of conventional serologic assays for disease diagnosis and infection monitoring. J Med Virol 2020. https://doi.org/10.1002/jmv.25702 PMid:32031264 PMCid:PMC7167054 